\title{
Water deprivation drives intraspecific variability in lizard heat tolerance
}

\author{
Salvador Herrando-Pérez ${ }^{\mathrm{a}, \mathrm{b}}, *$, Josabel Belliure ${ }^{\mathrm{c}}$, Francisco Ferri-Yáñez ${ }^{\mathrm{d}}$, \\ Matthijs P. van den Burg ${ }^{\mathrm{b}}$, Wouter Beukema ${ }^{\mathrm{e}}$, Miguel B. Araújo ${ }^{\mathrm{b}, \mathrm{f}}$, \\ John S. Terblanche ${ }^{\mathrm{g}}$, David R. Vieites ${ }^{\mathrm{b}}$
}

\author{
${ }^{a}$ School of Biological Sciences, The University of Adelaide, Adelaide, South Australia 5000, Australia \\ ${ }^{\mathrm{b}}$ Department of Biogeography and Global Change, Museo Nacional de Ciencias Naturales, Spanish National Research \\ Council (CSIC), c/ José Gutiérrez Abascal 2, 28006 Madrid, Spain \\ ${ }^{\mathrm{c}}$ Department of Life Sciences, Universidad de Alcalá, 28871 Alcalá de Henares, Spain \\ ${ }^{\mathrm{d}}$ Department of Community Ecology, Helmholtz Centre for Environmental Research (UFZ). Theodor-Lieser-Straße 4, \\ 06120 Halle (Saale), Germany \\ ${ }^{\mathrm{e}}$ Wildlife Health Ghent, Department of Pathology, Bacteriology and Poultry Diseases, Ghent University, Salisburylaan \\ 133, 9820 Merelbeke, Belgium \\ ${ }^{\mathrm{f}}$ Rui Nabeiro Biodiversity Chair, Universidade de Évora, Largo dos Colegiais, Évora, Portugal \\ ${ }^{\mathrm{g}}$ Centre for Invasion Biology, Department of Conservation Ecology and Entomology, Stellenbosch University, \\ Stellenbosch 7600, South Africa
}

Received 12 January 2020; accepted 6 August 2020

Available online 10 August 2020

\begin{abstract}
Quantifying intraspecific variation in heat tolerance is critical to understand how species respond to climate change. In a previous study, we recorded variability in critical thermal maxima $\left(\mathrm{CT}_{\max }\right)$ by $3{ }^{\circ} \mathrm{C}$ among populations of small Iberian lizard species, which could substantially influence predictions of climate-driven activity restriction. Here, we undertake experiments to examine whether we could reproduce similar levels of heat-tolerance variability in response to water deficit. We hypothesized that deprivation of drinking water should increase variability in $\mathrm{CT}_{\max }$ between populations more than deprivation of food under the theoretical expectation that the variation of the more limiting resource must trigger stronger variation in physiological performance. We measured $\mathrm{CT}_{\max }$ after manipulating availability of live prey and drinking water in two populations of an arid and a mesic lizard species from the Iberian Peninsula. We quantified a mean $\mathrm{CT}_{\max }$ across all studied lizards of $44.2^{\circ} \mathrm{C} \pm 0.2$ SE for the arid species and $41.7^{\circ} \mathrm{C} \pm 0.3 \mathrm{SE}$ for the mesic species. Using multimodel inference, we found that water deprivation (combined with food supply) caused population differences in $\mathrm{CT}_{\max }$ by 3 to $4{ }^{\circ} \mathrm{C}$ which were two to three times wider than population differences due to food deprivation (combined with water supply) or to food and water provision. To highlight the need for more thermo-hydroregulatory research, we examined bias in research effort towards thermal versus hydric environmental effects on heat tolerance through a systematic literature review. We show that environmental temperature has been used five times more frequently than precipitation in ecological studies of heat tolerance of terrestrial species. Studies linking thermal tolerance of ectotherms to the interplay of air temperature and water availability are needed in the face of projected increases in
\end{abstract}

\footnotetext{
*Corresponding author at: School of Biological Sciences, The University of Adelaide, Adelaide, South Australia 5000, Australia.

E-mail addresses: salvador.herrando-perez@adelaide.edu.au, salherra@gmail.com (S. Herrando-Pérez).
} 
aridity and drought in the 21 st century, because the balance of body temperature and water resources are functionally interlinked.

(C) 2020 Gesellschaft für Ökologie. Published by Elsevier GmbH. All rights reserved.

Keywords: Acanthodactylus; Climate change; $\mathrm{CT}_{\max }$; Drought; Ecophysiology; Macroecology; Phenotypic variance; Podarcis; Precipitation; Specialization; Thermo-hydroregulation

Life - at least life as we know it - should not exist without liquid water, even if energy conditions are optimal and all other essential matter conditions are non-limiting (O'Brien, 2006)

\section{Introduction}

Anthropogenic climate change is causing an expansion of drylands (Huang, Yu, Guan, Wang, \& Guo, 2016) since the beginning of the 20th century (Marvel, Cook, Bonfils, Durack, \& Smerdon, 2019). Current climate model projections indicate that aridification (Park, Jeong, Joshi, Osborn, \& Ho, 2018) and increased frequency and severity of droughts (Trenberth, Dai, van der Schrier, Jones, \& Barichivich, 2013) will be intensified in a 'business-as-usual' emission scenario and represent one of the major climate hazards to human societies and ecosystem services (Mora, Spirandelli, Franklin, Lynham, \& Kantar, 2018). Consequently, since many species are bound to experience increased dehydration stress, understanding how water availability affects their thermal tolerance is crucial (Kearney, Simpson, Raubenheimer, \& Kooijman, 2013; Mitchell, Boardman, Clusella-Trullas, \& Terblanche, 2017; Rozen-Rechels, Dupoué, Lourdais, Chamaillé-Jammes, \& Meylan, 2019).

Globally, water-temperature dynamics act as an eco-evolutionary force shaping biotic interactions, species ranges and diversity (O'Brien, 2006), and precipitation drives evolutionary change more strongly than temperature in plants and animals (Siepielski, Morrissey, Buoro, Carlson, \& Caruso, 2017). As the climate changes, Bonebrake and Mastrandrea (2010) project that decreased precipitation and elevated temperature should depress population fitness in high and low altitudes, respectively, while the margins of the southern or warmer ranges of many species in the Northern Hemisphere might be determined by precipitation more strongly than by temperature (Sunday, Bates, \& Dulvy, 2012; Thomas \& Lennon, 1999). Additionally, clines of thermal performance (Clusella-Trullas, Blackburn, \& Chown, 2011) and species richness (Latimer, 2007) have been shown to be best predicted by geographical variation in water availability (mediated largely by rainfall), or its interplay with environmental temperatures (Hawkins, Field, Cornell, Currie, \& Guégan, 2003; Kellermann, Overgaard, Johannes, Hoffmann, Ary A., Fløjgaard, Camilla, \& Svenning, Jens-
Christian, 2012; Razgour, Persey, Shamir, \& Korine, 2018). In that respect, precipitation outperforms environmental temperature in predictions of lizard activity, habitat requirements and/or distributional ranges (Kearney, Munns, Moore, Malishev, \& Bull, 2018; Sousa-Guedes, Arenas-Castro, \& Sillero, 2020), can accelerate population extirpation where rainfall fluctuates considerably (McLaughlin, Hellmann, Boggs, \& Ehrlich, 2002), multiplies extinction risk relative to predictions based on climate warming alone (McCain \& Colwell 2011) and, in combination with temperature, drives habitat preferences leading species to switch to open agricultural land in wet regions and the shelter of forests in dry regions (Frishkoff, Karp, Flanders, Zook, \& Hadly, 2016). Those broad macroecological patterns need to be examined functionally, with a focus on interactions among components of climate and species traits, so species' abilities to cope with climatic shifts and varying access to free-standing water are adequately understood (Rozen-Rechels, Dupoué, Lourdais, Chamaillé-Jammes, \& Meylan, 2019).

Recent developments highlight that the heat tolerance of vertebrate ectotherms is highly variable within the distribution of individual species (Clusella-Trullas \& Chown 2014). Critically, intraspecific variability in heat tolerance can severely alter predictions of the impacts of climate change on those animals and therefore needs to be investigated in detail (Herrando-Pérez, Ferri-Yáñez, Monasterio, Beukema, \& Gomes, 2019; Sinclair, Marshall, Sewell, Levesque, \& Willett, 2016; Valladares, Matesanz, Guilhaumon, Araújo, \& Balaguer, 2014). Access to free-standing water represents one of the key drivers by which species might modify their heat tolerance to cope with thermal stress. This notion has been recently branded as 'thermo-hydroregulation' whereby the regulation of body temperature and water balance are functionally integrated at the organismal and population levels and bound to experience behavioural and physiological trade-offs (Rozen-Rechels, Dupoué, Lourdais, ChamailléJammes, \& Meylan, 2019). Where thermo-hydroregulation and heat tolerance have been studied in controlled experiments using model invertebrates, there are contrasting results depending on study species, choice of heat-tolerance metric, and experimental setup (Chown, Sørensen, \& Terblanche, 2011; Mitchell, Boardman, Clusella-Trullas, \& Terblanche, 2017). For instance, in vinegar flies (Drosophilidae) tolerance to high temperatures decreased from humid to dry conditions despite that its heritability peaked in arid conditions (Bubliy, Kristensen, Kellermann, \& Loeschcke, 2012). 
By contrast, considering that animals can obtain water via food resources and directly drinking, fruit flies (Tephritidae) deprived of access to water showed decreased heat knockdown time, but only if combined with food deprivation, and treatments did not affect the expression profiles of heatshock proteins (Mitchell, Boardman, Clusella-Trullas, \& Terblanche, 2017). Given that insects are highly sensitive to variation in rainfall and water availability, owing to their small body size that drives a high surface area to volume ratio, and thus high susceptibility to evaporative water loss and limited capacity to carry water (Chown, Sørensen, \& Terblanche, 2011), it could be argued that these experiments should bear limited relevance for vertebrate ectotherms.

Lizards constitute a zoological group that has historically attracted a great deal of ecophysiological and evolutionary research (Camargo, Sinervo, \& Sites, 2010; Clusella-Trullas \& Chown 2014; Wollenberg Valero, Marshall, Bastiaans, Caccone, \& Camargo, 2019). In small species, water supply has been recognized as a major source of experimental bias in measuring thermal traits (Camacho \& Rusch 2017). Lorenzon, Clobert, Oppliger, \& John-Alder (1999) found that individuals of the viviparous lizard Zootoca vivipara subject to water shortage had reduced growth rates and activity and selected for lower body temperatures, and argued that “. ..there is population variability in phenotypic plasticity with respect to water availability in the habitat". In previous research with Iberian lacertids, we have reported variability in critical thermal maxima $\left(\mathrm{CT}_{\max }\right)$ by up to $3{ }^{\circ} \mathrm{C}$ between populations of the same species. Such a magnitude of population-level variation in heat tolerance (relative to cold tolerance) might indicate that heat tolerance is finely tuned to climatic variation, going unnoticed in global studies using macroclimatic predictors (HerrandoPérez, Monasterio, Beukema, Gomes, \& Ferri-Yáñez, 2020). Most importantly, choosing one representative population for the heat tolerance of a full species therefore becomes problematic in macro-ecological and physiological studies addressing climate impacts on hundreds to thousands of species (Herrando-Pérez, Ferri-Yáñez, Monasterio, Beukema, \& Gomes, 2019).

Here we examine whether we can experimentally reproduce similar levels of intraspecific variation in $\mathrm{CT}_{\max }\left(3^{\circ} \mathrm{C}\right)$ by modifying the availability of drinking water as a proxy for the extreme hydrological conditions the populations of a lizard species might experience in Iberia (Araújo, Thuiller, \& Pearson, 2006; Le Galliard, Massot, Baron, \& Clobert, 2012; Sousa-Guedes, Arenas-Castro, \& Sillero, 2020). Because dietary water can be an important source of water for reptiles (Congdon, Ballinger, \& Nagy, 1979; Nagy, 1972), we teased apart the effects of drinking water and food on $\mathrm{CT}_{\max }$ by letting two populations of two Iberian lizards have access to either or both resources. Under the theoretical expectation that the magnitude of variation of a driver of physiological stress should trigger proportional variation in physiological performance and/or specialization (Orlando \& Guillette 2001; Vamosi, Armbruster, \& Renner, 2014), we hypothesize that deprivation of the more limiting resource for thermal performance (i.e., drinking water) should cause greater difference in heat tolerance between populations of a species than a less limiting resource (i.e., dietary water or food) (Murphy \& Denardo 2019; Wright, 2013). We concur with others (Pirtle, Tracy, \& Kearney, 2019) that research efforts addressing the role of water in the thermal biology of species needs to be emphasized, as current studies focusing on climate impacts on biodiversity are heavily biased towards thermal effects. We support our claim by quantifying the frequency with which (i) air temperatures versus precipitation have been correlated with heat tolerance of terrestrial fauna and (ii) different metrics of thermal performance have been correlated with water resources for vertebrate ectotherms in the primary literature.

\section{Materials and methods}

We sampled two populations of each of two species of Iberian lizards, and measured their $\mathrm{CT}_{\max }$ in response to availability of food and/or water in laboratory conditions. We detail our sampling, experimental and statistical approach in the next three sections, and conclude by describing our literature review.

\section{Sampling}

Our two study species (Fig. 1) were the spiny-footed lizard Acanthodactylus erythrurus and the common wall lizard Podarcis muralis (Family Lacertidae). We selected them because they represent extremes of adaptation to xeric (A. erythrurus) versus mesic ( $P$. muralis) environments in Iberian reptiles (Speybroeck, Beukema, Bok, Van Der Voort, \& Velikov, 2016), and are widespread and abundant across most of their range. The Iberian distribution of both species is enveloped by a gradient of precipitation where sites with the highest rainfall coincide with lowest Winter (A. erythrurus) or Summer (P. muralis) temperatures (Appendix A: Fig. 2).

We caught, by noosing, 15 males from each of two populations of the two study species (Fig. 1; Appendix A: Fig. 1), namely (i) A. erythrurus from El Saler (Valencia, Eastern Spain: coastal dehesa combining dunes and Mediterranean scrub) and Chapinería (Madrid, Central Spain: inland dehesa combining dry grassland with sparse holm oak trees); and (ii) $P$. muralis from Peñagolosa (Castellón, Eastern Spain: mountain springs in temperate, mixed forest) and El Portalet (Huesca, The Pyrenees: rocky outcrops in peatland). Sampling took place in July 2015 (El Saler, Peñagolosa) and 2016 (Chapinería, El Portalet). We have observed P. muralis drinking directly from streams in the two study sites during Spring and Summer. As to A. erythrurus, lizards might have rare access to drinking water in a dune-dominated habitat (El Saler) and perhaps from puddles after storms in Chapinería, while dew drinking is unlikely because individuals 

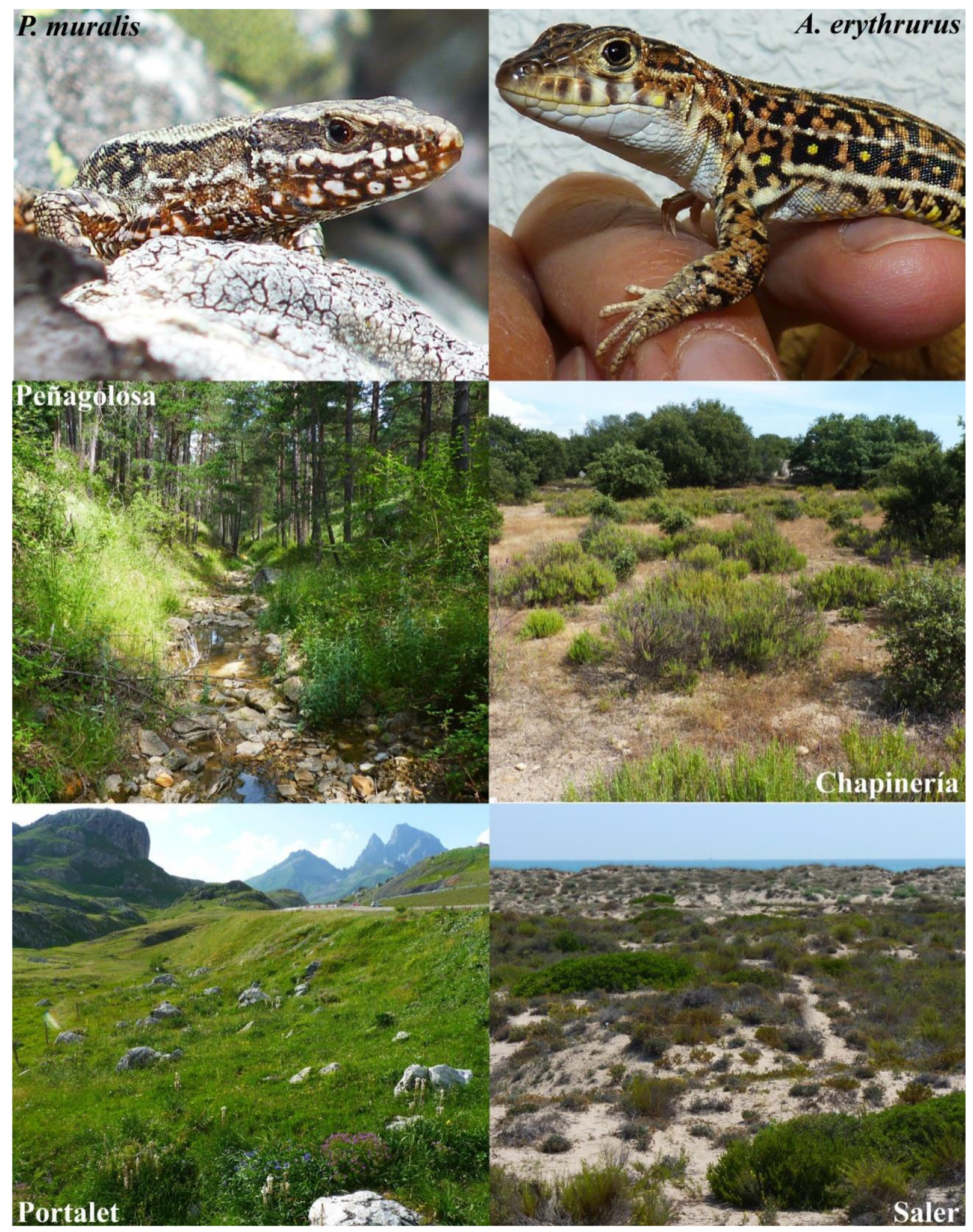

Fig. 1. Adult males of the two study species: the spiny-footed lizard Acanthodactylus erythrurus and the common wall lizard Podarcis muralis along with the four study localities in the Iberian Peninsula. Photo credits: Salvador Herrando-Pérez.

become active in sunny days at $\sim 10: 00 \mathrm{AM}-12: 00 \mathrm{PM}$ at the two study sites when dew has already evaporated. The latter species is mostly inactive on cloudy days (Belliure, 2015).

\section{Experiments}

Once in the lab, each lizard was housed in an individual terrarium, and acclimated to captivity from days 1 to 15 


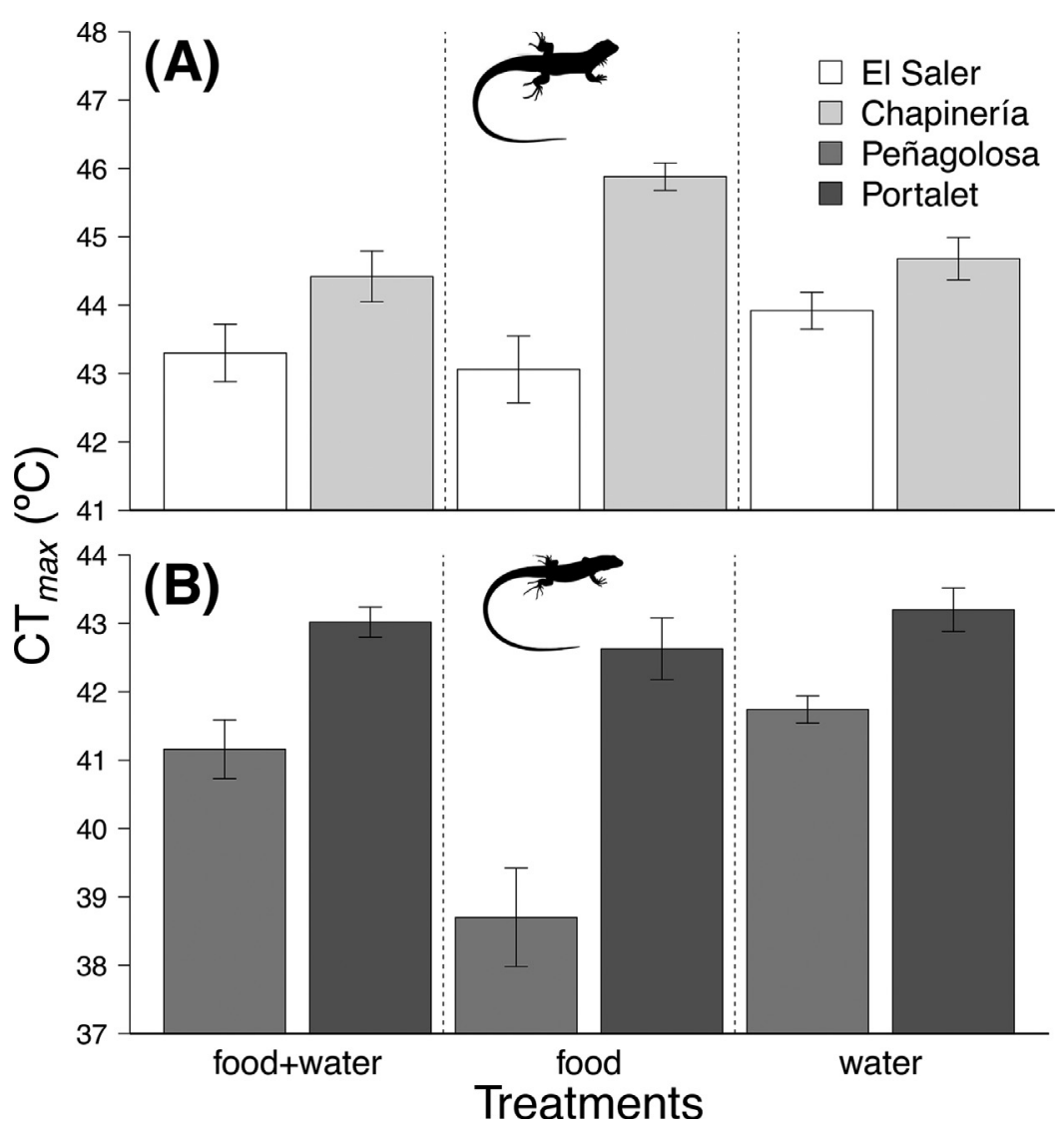

Fig. 2. Critical thermal maxima $\left(\mathrm{CT}_{\max }\right)$ of two populations from two Iberian species of lacertid lizards, including the spiny-footed lizard Acanthodactylus erythrurus (A) and the common wall lizard Podarcis muralis (B) in response to three experimental treatments (from left to right): provision of food and water, only food, and only water. Bars quantify mean $\mathrm{CT}_{\max } \pm \mathrm{SE}$. Sample size $=5$ male adults per population and treatment, except 3 males for only-food treatment for $P$. muralis from Portalet.

following capture. On day 1 of every study year, the batch of 30 terraria was positioned in three contiguous rows in a greenhouse at ambient temperature and moisture covered by a sunshade $2 \mathrm{~m}$ above ground level. The sunshade allowed sun exposure in different parts of the setting during different times of the day; preliminary data from empty terraria over a two-week period showed that daily maximum temperatures within terraria closely followed maximum temperatures at local meteorological stations (Spanish Agency of Meteorology, www.aemet.es), i.e., a maximum of $35^{\circ} \mathrm{C}$ when terraria were under shade and a minimum of $30^{\circ} \mathrm{C}$ when exposed to direct sunlight. Each terrarium had a substrate of coconut fiber and included a ceramic brick for shelter and thermoregulation. Lizards emerged from their shelter from 9:30 to 11:00 AM (conditional on cloudiness), and we then provided them daily with spring water (a full Petri dish placed in the lower-left corner of each terrarium) along with live prey (dropped at the upper side of each terrarium). Based on captivity experiments with lacertids (Herrando-Pérez, FerriYáñez, Monasterio, Beukema, \& Gomes, 2019), we gave each lizard a daily meal of three prey items, systematically providing the same combination of mealworms (Tenebrio mollitor), waxworms (Galleria mellonella) and house crickets (Acheta domesticus) for each individual.
On day 15, all individuals had weights similar to those of their day of capture and consumed their prey items daily. Thereafter, from day 16 to 26, we allocated each lizard from each population randomly to one of three treatments (number of lizards per population and treatment $=5$ ), namely provision of (i) food and water as in the acclimation phase (control treatment), (ii) only food or (iii) only water. To avoid edge effects in the experimental setting, we randomized the position of all terraria daily from day 1 to 26 . Two $P$. muralis/Portalet individuals in the 'food only' treatment escaped from their terraria prior to $\mathrm{CT}_{\max }$ estimation. A sample size of 3 males per population should accurately capture the mean population $\mathrm{CT}_{\max }$ estimated from larger sample sizes in our study species (Herrando-Pérez, Ferri-Yáñez, Monasterio, Beukema, \& Gomes, 2019), and is within the range of published work (e.g., Beal, Lattanzio, \& Miles, 2014; Muñoz, Langham, Brandley, Rosauer, \& Williams, 2016). To demonstrate the latter statistically, we applied a retrospective power analysis (Dean \& Voss 1999) to our linear models (detailed below).

We determined $\mathrm{CT}_{\max }$ on day 27 after capture through the dynamic method described by Lutterschmidt and Hutchison (1997). Following the protocol of previous research (Herrando-Pérez, Ferri-Yáñez, Monasterio, Beukema, \& 
Gomes, 2019), and for each study population, we carefully inserted a thermocouple 1 to $2 \mathrm{~cm}$ into the cloaca of each lizard - to avoid internal damage, the apical sensor was coated with a minute drop of nail polish (left to dry out overnight) and the thermocouple was further coated with pure vaseline during the experiments. The thermocouple was wired to a HH-25TC Omega ${ }^{\circledR}$ Thermometer via a $1 \mathrm{~m}$-long cable (made up of flexible polytetrafluoroethylene). For each lizard, we fastened a $2 \times 5 \mathrm{~cm}^{2}$ strip of parafilm to secure the distal part of the cable (equipped with the thermocouple) ventrally against the cloaca. Thereafter, lizards were kept some $30 \mathrm{~cm}$ below a red-heat lamp, and body temperatures were raised by $1{ }^{\circ} \mathrm{C} \times \min ^{-1}$. Throughout each trial, three of us in conjunction (JB, FFY, SHP) monitored body temperature and behavior, and ultimately measured $C T_{\max }$ as the cloacal temperature at which each lizard lost its righting response (Lutterschmidt \& Hutchison 1997).

We did not take pretreatment measurements of $\mathrm{CT}_{\max }$ because they would impact the fitness of the study individuals in our experiments and could introduce noise in the acclimatization period had the individuals experienced different thermal histories. For example, lizards can undergo short-term heat hardening after being exposed to their $\mathrm{CT}_{\max }$ (Gilbert \& Miles 2019; Phillips, Muñoz, Hatcher, Macdonald, \& Llewelyn, 2016) and thermal assays can have lasting effects on the fitness that are never assessed because of the short-term nature of those assays (Ribeiro, Camacho, \& Navas, 2012). Nonetheless, our estimates of $\mathrm{CT}_{\max }$ (see Results) fell within those observed for other Iberian populations of the same species, with heat tolerance varying from 44 to $47^{\circ} \mathrm{C}$ for $A$. erythrurus (5-7 males per population), and from 42 to $44^{\circ} \mathrm{C}$ for P. muralis (5 males per population) (Herrando-Pérez, Ferri-Yáñez, Monasterio, Beukema, \& Gomes, 2019). We prevented physiological/physical damage by holding lizards (up to their necks) in a water bath $\left(20-25{ }^{\circ} \mathrm{C}\right)$ immediately after each thermal shock, ultimately attaining $100 \%$ survival. We provided lizards with food and water ad libitum daily from day 27 (right after the $\mathrm{CT}_{\max }$ estimation) to 31 , and all individuals were released at their point of capture on day 32 from the onset of experiments. Latitude and longitude of study sites and body sizes and $\mathrm{CT}_{\max }$ per lizard individual are presented in Appendix B.

\section{Statistical analyses}

Throughout, all analyses and graphics were done in the $R$ environment (R Core Team, 2020). Our focus was on intraspecific variability in heat tolerance, rather than on interspecific patterns (see Garland \& Adolph, 1994). We tested the hypothesis that drinking-water deprivation should cause greater differences in heat tolerance between populations of a species than deprivation of food (see Introduction). So for each of the two study species separately, and with $\mathrm{CT}_{\max }$ as the common response, we contrasted the strength of statistical evidence for five linear models using the function $l m$ in the $R$ package stats (R Core Team, 2020), namely: $(i) \mathrm{CT}_{\max }$ $\sim 1$ (null model): $\mathrm{CT}_{\max }$ is indistinguishable among populations and treatments, i.e., identical intercept or mean $\mathrm{CT}_{\max }$ across populations; (ii) $\mathrm{CT}_{\max } \sim$ pop: $\mathrm{CT}_{\max }$ is populationdependent, i.e., different population intercepts irrespective of treatment, where pop = population identity; (iii) $\mathrm{CT}_{\max } \sim$ treat: $\mathrm{CT}_{\text {max }}$ is treatment-dependent, i.e., different treatment intercepts irrespective of population identity, where treat $=$ treatment; $(i v) \mathrm{CT}_{\max } \sim$ pop+treat: different population and treatment intercepts but the effect of one predictor on $\mathrm{CT}_{\max }$ does not depend on the effect of the other predictor (additive model); and $(v) \mathrm{CT}_{\max } \sim$ pop*treat: different population and treatment intercepts and the effect of one predictor on $\mathrm{CT}_{\max }$ depends on the effect of the other predictor (interaction model). Effectively, models (ii) and (iii) represent a one-way ANOVA, and models (iv) and ( $v$ ) represent a two-way ANOVA, while the output of $l m$ is directly transferable to an ANOVA table using the anova function in stats. Because individuals might adapt differently to captivity, we replicated our analyses above for a model set including 'body condition' (Schulte-Hostedde, Zinner, Millar, \& Hickling, 2005: residuals of the linear regression of body weight on snout-to-vent length) of each individual on day 26 of the experiment as an additional predictor in all models.

We ranked model support, based on the Akaike's Information Criterion adjusted to finite sample size $\left(\mathrm{AIC}_{c}\right)$ (Sugiura, 1978), by means of model probabilities $\left(w \mathrm{AIC}_{c}\right.$, which are scaled to a 0 to 1 interval) and evidence ratios of $w \mathrm{AIC}_{c}$ of the top-ranked model to the $w \mathrm{AIC}_{c}$ of every other model in the set (Burnham \& Anderson 2002). We assumed Gaussian errors (corroborated in the saturated model $\left[\mathrm{CT}_{\max }\right.$ $\sim$ pop*treat] by means of Q-Q and fit-versus-residual plots), and confirmed variance homogeneity using Bartlett's test (Bartlett, 1937). We quantified the power of the best supported model in the $R$ package powerMediation (Qiu, 2018) based on our sample size (3-5 males per population $\times$ treatment, see above), a $p$ value of 0.05 (probability of the data given that the null hypothesis is true), and an effect size of 3 (A. erythrurus) to $4{ }^{\circ} \mathrm{C}$ (P. muralis) - see Results.

\section{Literature review}

We carried out two literature reviews using strings of key words combined by Boolean operators in Scopus covering the period 1970-2019 (see full details in Appendix C).The results of both reviews were plotted in bipartite-network graphs using the $R$ package igraph (Csárdi \& Nepusz 2006). While our focus is on drinking-water availability, the effects of both internal hydration status and free-standing water availability are partly conflated in our review of the ecological literature, and should not be confused.

In the first review ('general literature review', Scopus accessed on 01/05/2019), we asked whether authors 
documenting a relationship between climate and animal heat tolerance had chosen (i) climatic metrics of temperature and/ or precipitation and (ii) particular taxa. We combined expressions of heat tolerance widely used across terrestrial invertebrates and vertebrates (i.e., ' $\mathrm{CT}_{\max }$ ' $\mathrm{OR}$ 'heat tolerance' OR 'thermal maximum' OR 'thermal maxima' OR 'upper critical temperature' OR 'upper lethal temperature' OR 'upper thermal' (but excluding some taxa-specific expressions like 'heat coma' mainly used in arthropod research) with the wildcard *climat* — we excluded the terms 'temperature' or 'precipitation' so as to prevent a bias for either metric. We restricted our search to the main-stream ecological journals, namely Ecology $(N=7$ papers matching our search criteria), Ecology Letters $(N=6)$, Functional Ecology $(N=22)$, Journal of Animal Ecology $(N=4)$, Oeco$\operatorname{logia}(N=14)$ and Oikos $(N=6)$, along with Global Ecology and Biogeography $(N=6)$ given its coverage of large-scale ecological patterns. We excluded journals focused on thermal biology (e.g., Journal of Thermal Biology) because they would have introduced directional bias towards studies using temperature predictors. In total, we collated a set of 64 target papers. For each target paper, we recorded the taxonomic group studied (amphibia, arthropoda, aves, mammalia, reptilia) and the broad climate metric being used (temperature, precipitation). We then counted as 'one case' each time a climate metric had been used at least once in a statistical analysis for one of our study taxa, giving a total of 95 'cases' across the 64 target papers. A total of 61 papers contributed $1-3$ cases, and 3 papers contributed 4,5 and 8 cases, respectively. For instance, a paper using temperature data for reptiles would amount to 1 case, a paper using precipitation data for birds and reptiles would include 2 cases, and a paper using precipitation and temperature data for birds and reptiles would amount to 4 cases or climate $\times$ taxa combinations.

In the second Scopus-based literature review ('focal literature review'), we quantified the frequency with which herptile heat tolerance (our main focus) has been predicted from variation in environmental water (experimental dehydration, humidity/moisture, lentic/lotic water bodies, precipitation/ rainfall) in studies focusing on the interplay of hydric and thermal herptile physiology. We first used a pilot string of key words to identify the most common terms referring to metrics of thermal performance and water resources (Scopus accessed on 01/04/2018). Then, we used those terms to do a second browsing of papers (06/04/2019), giving a total of 56 target papers. From each target paper, we extracted the name of the study species and locality, and of the metrics of water and temperature used in quantitative analyses. We finally counted the number of times ('cases') a metric of thermal physiology had been predicted from a metric of environmental water, resulting in 53 cases across the 56 target papers. A total of 49 papers contributed $1-3$ cases, and 7 papers contributed 4 to 6 cases. For instance, a paper predicting preferred body temperature from experimental dehydration treatments would include 1 case, and a paper predicting cold and heat tolerance through a moisture gradient would include 2 cases. We lastly classified and counted all cases where a thermal or hydric variable had been used as response or predictor in quantitative analyses.

\section{Results}

\section{Physiological metrics}

We found that the overall mean $\mathrm{CT}_{\max }$ among all individuals and treatments was on average $2.5{ }^{\circ} \mathrm{C}$ higher for the (arid-adapted) spiny-footed lizard Acanthodactylus erythrurus $\left(44.2{ }^{\circ} \mathrm{C} \pm 0.2 \mathrm{SE}\right)$ than for the (mesic-adapted) common rock wall lizard Podarcis muralis $\left(41.7^{\circ} \mathrm{C} \pm 0.3 \mathrm{SE}\right)$ as previously observed with other Iberian populations of both species (see Materials and methods).

We contrasted statistical evidence for five linear models (Table 1) capturing whether $\mathrm{CT}_{\max }$ varied with population identity and/or experimental treatment (provision of food and water, only food, only water) for each species separately. The interaction model explained $56-73 \%$ of the variation in $\mathrm{CT}_{\max }$, and was 1-9 orders of magnitude more likely than the four alternative models (Table 1). The former model supports that differences in $\mathrm{CT}_{\max }$ between populations depended on treatment (Fig. 2). Thus, lizards having access to food and water, or only water, showed betweenpopulation differences in mean $\mathrm{CT}_{\max }$ of only 1 (A. erythrurus) to $2{ }^{\circ} \mathrm{C}$ ( $P$. muralis), but deprivation of water combined with food supply more than doubled population-level differences in mean $\mathrm{CT}_{\max }$ by up to 3 to $4{ }^{\circ} \mathrm{C}$, respectively (Fig. 2).

For both species, and for sample sizes of 3-5 males per population $\times$ treatment, our two-way ANOVA interaction model had a statistical power (i.e., probability of the data if the null hypothesis is false) of 0.83 (A. erythrurus) and 0.97 (P. muralis). Controlling for lizard body condition resulted in equivalent statistical support for, and variance explained by, the interaction model (Appendix A: Table 1), with population differences in heat tolerance peaking in the only treatment where lizards had no access to drinking water.

\section{Publication metrics}

Among the 64 ecological papers investigating heat tolerance and including quantitative analysis of climate metrics ('general literature review', see Materials and methods), ectotherms (arthropoda, amphibians, reptiles) and endotherms (birds, mammals) were used in $88 \%$ and $14 \%$ of the papers (Fig. 3), respectively. Across those papers, quanitative analyses ('cases', see Materials and methods) using environmental temperature data (84\%) outnumbered those using precipitation data (16\%) (Fig. 3), and those proportions were of similar magnitude for papers published after 2010 (Appendix C). 
Table 1. Probabilities, evidence ratios, and variance explained for linear models equating critical thermal maxima $\left(\mathrm{CT}_{\max }\right)$ as a function of population ( rurus (Chapinería, El Saler) and the common wall lizard Podarcis muralis (Peñagolosa, Portalet) in the Iberian Peninsula, each subject to three experimental treatments (provision of both food and water, only food, or only water).

\begin{tabular}{lllll}
\hline Species & Models & Model probability $\left(w \mathrm{AIC}_{c}\right) *$ & Evidence ratio $(\mathrm{ER}) *$ & Variance explained $(\%)$ \\
\hline Spiny-footed lizard & $\mathrm{CT}_{\text {max }} \sim$ pop $\times$ treat & 0.99 & 1.0 & 55.8 \\
& $\mathrm{CT}_{\text {max }} \sim$ pop + treat & $6.6 \mathrm{E}-03$ & $1.5 \mathrm{E}+02$ & 43.0 \\
& $\mathrm{CT}_{\text {max }} \sim$ pop & $1.7 \mathrm{E}-03$ & $5.7 \mathrm{E}+02$ & 42.2 \\
& $\mathrm{CT}_{\text {max }} \sim$ treat & $5.8 \mathrm{E}-07$ & $1.7 \mathrm{E}+06$ & $<1$ \\
& $\mathrm{CT}_{\text {max }} \sim 1$ & $2.8 \mathrm{E}-07$ & $3.6 \mathrm{E}+07$ & - \\
Common wall lizard & $\mathrm{CT}_{\text {max }} \sim$ pop $\times$ treat & 0.99 & 1.0 & 73.3 \\
& $\mathrm{CT}_{\text {max }} \sim$ pop + treat & $1.1 \mathrm{E}-02$ & $8.9 \mathrm{E}+01$ & 66.3 \\
& $\mathrm{CT}_{\text {max }} \sim$ pop & $4.9 \mathrm{E}-06$ & $2.0 \mathrm{E}+05$ & 46.1 \\
& $\mathrm{CT}_{\text {max }} \sim$ treat & $7.0 \mathrm{E}-08$ & $1.4 \mathrm{E}+07$ & 23.9 \\
\hline
\end{tabular}

$*$ Model probabilities $\left(w \mathrm{AIC}_{c}\right)$ and evidence ratios $\left(\mathrm{ER}=w \mathrm{AIC}_{c}\right.$ of top-ranked model to $w \mathrm{AIC}_{c}$ of any given model) obtained through the Akaike Information Criterion adjusted for finite sample size $\left(\mathrm{AIC}_{c}\right)$, and variance explained $(\%)$ estimated by linear models with Gaussian errors. Sample size $=5$ male adults per population and treatment, except 3 males for the only-food treatment for $P$. muralis from Portalet.

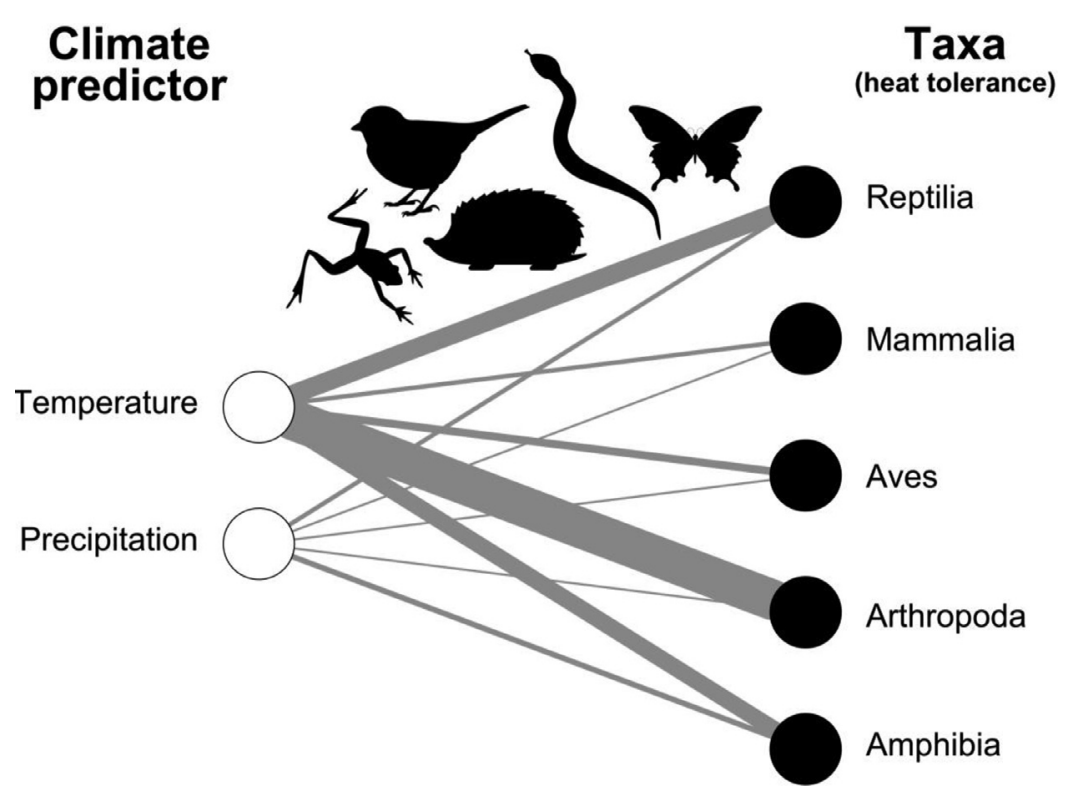

Fig. 3. Frequency of correlations between climate (air temperature versus precipitation) and heat tolerance of terrestrial fauna in the ecological literature (general literature review $=64$ papers, 95 cases; thickest link $=36$ cases, thinnest link $=2$ cases).

On the other hand, from a total of 56 papers reporting correlations between thermal physiology and water resources for herptiles ('focal literature review', see Materials and methods), 40 predicted a physiological thermal metric from a water-related metric (Table 2; Appendix A: Fig. 3). The most used responses were (preferred) body temperature $(60 \%$ of the cases) and heat tolerance (19\%), respectively, while the most popular predictors were dehydration and moisture gradients and wet versus dry seasonality (25-30\% each). Across statistical correlations of any sort, body temperature $(23 \%)$ and evaporative water loss $(26 \%)$ were the most common 'responses', while temperature and moisture gradients predominated as 'predictors' (29\%) (Table 2; Appendix A: Fig. 3).
Overall, the average published ecophysiological paper is one looking into temperature effects on arthropods (Fig. 3), particularly insects. This indicates the importance of insects to agriculture and human health, less restrictive ethical considerations for undertaking thermal experiments for invertebrates than for vertebrates, ease of laboratory rearing, as well as the much higher species richness of the former. When water variables are included in ecophysiological studies of ectotherms (Table 2), the prevailing focus is on how species manage their water balance and thermal performance in order to respond to environmental change once water has been assimilated in their bodies, often by monitoring and/or modeling evaporative water loss. 
Table 2. Frequency of relationships ('cases', see Materials and methods) of water- and temperature-related metrics of herptile physiology in response to water and temperature predictors in 56 target papers from the ecophysiological literature (focal literature review). Percentages (\%) estimated for responses and predictors separately.

\begin{tabular}{|c|c|c|c|c|}
\hline Statistical treatment & Variable type & Variable & Frequency & $\%$ \\
\hline \multirow[t]{9}{*}{ Response } & \multirow[t]{5}{*}{ Temperature } & Body temperature & 21 & 24 \\
\hline & & Preferred body temperature & 15 & 17 \\
\hline & & Heat tolerance & 12 & 14 \\
\hline & & Cold tolerance & 6 & 7 \\
\hline & & Operative temperature & 4 & 5 \\
\hline & \multirow[t]{2}{*}{ Water } & Evaporative water loss & 23 & 26 \\
\hline & & Body dehydration & 4 & 5 \\
\hline & \multirow[t]{2}{*}{ Other } & Running speed & 1 & 1 \\
\hline & & Heart rate & 2 & 2 \\
\hline \multirow[t]{6}{*}{ Predictor } & \multirow[t]{2}{*}{ Temperature } & Temperature gradient & 25 & 29 \\
\hline & & Body temperature & 2 & 2 \\
\hline & \multirow[t]{4}{*}{ Water } & Moisture gradient & 20 & 24 \\
\hline & & Body dehydration & 18 & 21 \\
\hline & & Wet-dry seasonality & 16 & 19 \\
\hline & & Evaporative water loss & 4 & 5 \\
\hline
\end{tabular}

\section{Discussion}

Understanding how thermal tolerance varies within and among species has long been recognized as a critical area of ecophysiological research (Brattstrom, 1968; Congdon, Ballinger, \& Nagy, 1979; Hertz, Arima, Harrison, Huey, \& Losos, 2013) and is now of crucial importance to predict how ectotherms might respond to ongoing and future climate change (Clusella-Trullas \& Chown 2014; HerrandoPérez, Ferri-Yáñez, Monasterio, Beukema, \& Gomes, 2019; Sinclair, Marshall, Sewell, Levesque, \& Willett, 2016). Our experiments indicate that deprivation of drinking water can accentuate the variation of heat tolerance between populations of ectothermic species by up to $4{ }^{\circ} \mathrm{C}$ - which exceeds our previous estimates of heat-tolerance shifts $\left(3{ }^{\circ} \mathrm{C}\right)$ among populations of species of Iberian lacertids (HerrandoPérez, Monasterio, Beukema, Gomes, \& Ferri-Yáñez, 2020). Such population differences can lead to differences in species-level estimates of restricted activity by more than 20 days (Herrando-Pérez, Ferri-Yáñez, Monasterio, Beukema, \& Gomes, 2019). For terrestrial ectotherms from the Northern Hemisphere, $4{ }^{\circ} \mathrm{C}$ variation in $\mathrm{CT}_{\max }$ represents about $20 \%$ of the interspecific variation in $\mathrm{CT}_{\max }$, and $50 \%$ the total interspecific variation in $\mathrm{CT}_{\text {max }}$ previously recorded for the latitudinal band of the Iberian Peninsula (estimated from Bennett, Calosi, Clusella-Trullas, Martínez, \& Sunday, 2018), and thus requires careful examination in macrophysiological, biogeographical and evolutionary research.

Overall, our study attempts $(i)$ to connect with the large body of ecophysiological studies undertaken by the middle of the 20th century (reviewed by Cowles \& Bogert 1944; Lillywhite, 2006) on the interaction of water and thermal physiology, and (ii) to promote the ongoing reunification of ecology with physiology (Gaston, Chown, Calosi, Bernado, \& Bilton, 2009) under climate change. The challenges faced by macrophysiology (Chown \& Gaston 2016), and their application to understanding mechanisms underlying broadscale ecological patterns of endotherms and ectotherms (Buckley, Hurlbert, \& Jetz, 2012), concentrate on species responses to environmental temperatures. Fewer studies (by a factor of 5 in our literature review; Fig. 3) have assessed the extent to which ectotherm thermal tolerance and stress vary as a function of water availability in the environment, and much fewer considered how an organism's water balance might interact with thermoregulatory behavior and stress resistance (Pirtle, Tracy, \& Kearney, 2019; RozenRechels, Dupoué, Lourdais, Chamaillé-Jammes, \& Meylan, 2019; see Introduction). This knowledge gap represents an impediment for the functional analyses and understanding of large-scale ecophysiological patterns, but also provides opportunity to contribute novel ecological information to multidisciplinary drought research in a changing climate (Ault, 2020). Indeed, the organismal responses to drought should be regarded as a form of biological drought index to track departures from mean conditions. Climatologists are striving to narrow the uncertainty of drought and precipitation predictions under climate change (Ault, 2020), and ecologists should endeavor to improve the mechanistic links between water availability and the fitness of organisms (Bonebrake \& Mastrandrea 2010; McCain \& Colwell 2011; Rozen-Rechels, Dupoué, Lourdais, Chamaillé-Jammes, \& Meylan, 2019) at the population and species levels.

We currently ignore the extent by which spatial mosaics of heat tolerance (Sears, Raskin, \& Angilletta, 2011) are determined by water availability. Thermodynamic niche models partly pursue that goal by acknowledging that the responses of organisms to their environments must be mediated by food-temperature-water interactions in a spatiallyexplicit context (Kearney, Simpson, Raubenheimer, \& Kooijman, 2013). In a ground-breaking contribution using 
those models, Kearney, Munns, Moore, Malishev, \& Bull (2018) found that growth and body condition of the sleepy lizard Tiliqua rugosa (given spatially constant metrics of thermal performance) could be best predicted by assuming that individuals had access to drinking water relative to dietary water and rainfall, while the dry-continental distribution margins of this Australian species mostly responded to water limitation. These authors conclude that "....water can be more important than temperature in constraining the activity, habitat requirements, and distribution limits of terrestrial ectotherms". Indirectly, Kearney, Munns, Moore, Malishev, \& Bull (2018) imply that precipitation can alter the amounts of humidity and drinking water in the environment, and all of these three factors can have strikingly different effects on the physiology of organisms (Dupoué, Rutschmann, Le Galliard, Clobert, \& Blaimont, 2018; Lorenzon, Clobert, Oppliger, \& John-Alder, 1999).

The factors shaping thermo-hydroregulatory strategies are expected to be complex, so we provide in the following a few examples (see also Introduction). Low precipitation can markedly augment the impacts of temperature extremes on fitness (Wang, Zeng, Li, Bi, \& Du, 2016) and curtail the microhabitat quality of thermal refugia (Scheffers, Edwards, Diesmos, Williams, \& Evans, 2014). For instance, lizards can prefer tree-shaded spots in dry periods but sun-exposed microhabitats with larger foraging areas after storms (Ryan, Latella, Giermakowski, Snell, \& Poe, 2016), and wet over dry refuges as temperature increase (Pintor, Schwarzkopf, \& Krockenberger, 2016) or cold over warm refuges under water restriction (Rozen-Rechels, Badiane, Agostini, Meylan, \& Le Galliard, 2020). In temperate mesic-adapted lizards, males are smaller and experience higher survival than females with increased humidity (Romero-Diaz, Breedveld, \& Fitze, 2017). Additionally, lizards can accentuate evaporative water loss in mesic environments (Belasen, Brock, Li, Chremou, \& Valakos, 2017) and lower basal hormonal levels, critical to modulate daily and seasonal activity, when faced with shortage of freestanding water (Dupoué, Rutschmann, Le Galliard, Clobert, \& Blaimont, 2018). Behavioural adjustments can relax selective pressure at the expense of adaptation of thermal tolerance in the long-term (Buckley, Ehrenberger, \& Angilletta, 2015), but might incur fitness costs and further widen differences in heat tolerance between populations of species exposed to contrasting water resources. Across the board, it is important to recognize that ectotherm ecophysiological research exclusively looking at experimental air-temperature effects does not neglect drinking water per se but supply it to individuals ad libitum so that it does not affect the interpretation of results.

Disentangling the relative contribution of phenotypic plasticity (e.g., seasonal acclimatization) and genetic adaptation to intraspecific variation in heat tolerance variation remains one of the main challenging areas for future ecophysiological research (discussed by Diamond, 2017; Herrando-Pérez, Ferri-Yáñez, Monasterio, Beukema, \& Gomes, 2019). Compared to many vertebrate endotherms, most herptiles are characterized by limited dispersal and, consequently, they are highly constrained to track future climate changes (Araújo \& Pearson 2005), thereby prompting local ecophysiological responses for persistence. In that context, drinking-water availability can act as an evolutionary driver and as an amplifier of ectotherm physiological plasticity. Additionally, thermal and hydric requirements might conflict with or trade off in lizard microhabitat selection and activity patterns and complicate ectotherm responses to climate change (Pirtle, Tracy, \& Kearney, 2019). This seems a critical area of future development including experimental settings where we can discriminate ecophysiological responses to varying temperature and drinking-water conditions, and scaling up those responses at broad spatial scales. For example, the size and number of scales partly determines evaporative water loss, varies with aridity and precipitation both intra- and inter-specifically (Calsbeek, Knouft, \& Smith, 2006; Oufiero, Gartner, Adolph, \& Garland, 2011; Soulé, 1966; Wegener, Gartner, \& Losos, 2014), and could therefore modify lizard heat tolerance and also be subject to natural selection for varying water conditions.

The reality is that the whole Mediterranean basin is currently exposed to the synergistic effects of drought and warming. Thus, low soil moisture in Spring and early Summer are amplifying the incidence of heatwaves in the hottest months (Dasari, Salgado, Perdigao, \& Challa, 2014; Russo, Gouveia, Dutra, Soares, \& Machado Trigo, 2019), and their magnitude is projected to increase across most of Iberia (Dasari, Salgado, Perdigao, \& Challa, 2014). In drylands and during droughts, herptiles might rely on rapid adaptive and/or plastic responses for survival, particularly in the southwest of Europe where many reptiles are projected to lose climate space due to the combination of increased warming and decreased precipitation (Araújo, Thuiller, \& Pearson, 2006; Le Galliard, Massot, Baron, \& Clobert, 2012). Range-restricted species such as small lizards are predicted to experience higher precipitation seasonality than broad-range species $(\mathrm{Li}, \mathrm{Li}$, Sandel, Blank, \& Liu, 2015). Those climate shifts might be critical for population persistence in the periphery of the thermal niche of species (Lancaster, 2016; Prieto-Ramirez, Pe'er, Rödder, \& Henle, 2018; Valladares, Matesanz, Guilhaumon, Araújo, \& Balaguer, 2014) and across altitudinal gradients (McCain \& Colwell 2011).

\section{Conclusions}

We contend that local populations of small herptiles are constrained to adjust their thermoregulatory, feeding and reproductive behavior to the availability of a limiting resource such as drinking water (Dupoué, Blaimont, Rozen-Rechels, Richard, \& Meylan, 2020; Dupoué, Rutschmann, Le Galliard, Miles, \& Clobert, 2017; Le Galliard, Massot, Baron, \& Clobert, 2012; Murphy \& Denardo 2019; Peterson, 1996). While global concerns have arisen because (i) ectotherms are narrowing their 
thermal safety margins as a result of a warming climate (Sunday, Bates, Kearney, Colwell, \& Dulvy, 2014) and (ii) predators relying on invertebrates, such as many reptiles like those studied here, are facing massive declines of their arthropod prey (Lister \& Garcia 2018; Sánchez-Bayo \& Wyckhuys 2019), increased aridification (Park, Jeong, Joshi, Osborn, \& Ho, 2018; Trenberth, Dai, van der Schrier, Jones, \& Barichivich, 2013) reducing the frequency or magnitude of pulses of free-standing water could pose even greater threat (Murphy \& Denardo 2019; Wright, 2013).

Terrestrial (micro)habitat quality can be severely constrained by the lack of environmental water, and in turn increase species extinction risk much more strongly than previously thought relative to aquatic species (Pinsky, Eikeset, McCauley, Payne, \& Sunday, 2019). Thermal refugia might be physically available but too dry for herptiles to maintain a homeostatic water balance and avoid physiological stress. From first principles, body temperature and water balance are functionally integrated for ectotherms to attain physiological homeostasis (RozenRechels, Dupoué, Lourdais, Chamaillé-Jammes, \& Meylan, 2019), so it is unsurprising that small herptile species that tolerate narrow ranges of environmental temperatures are those that also tolerate narrow ranges of precipitation regimes, and vice versa (Bonetti \& Wiens 2014). Due to the temperature-precipitation interactions imposed by multidimensional climate fluctuations (Garcia, Cabeza, Rahbek, \& Araújo, 2014; VanDerWal, Murphy, Kutt, Perkins, \& Bateman, 2013) and contrasting eco-evolutionary dynamics in the cold versus hot range margins of species distributions (Calosi, Bilton, Spicer, Votier, \& Atfield, 2010; Nadeau \& Urban 2019), we argue that a 'cold-hot' axis of covariation of thermal performance and thermoregulatory behavior (Goulet, Thompson, Michelangeli, Wong, \& Chapple, 2017) needs to be conceptualized against a 'dry-wet' axis to fully represent the thermal niche of ectotherm species and how they can tolerate and/or adapt to climate change.

\section{Authors' contributions}

SHP and DRV conceived the idea and designed methodology. JB, SHP and MPB sampled lizards in the wild. JB and SHP maintained lizards in captivity. JB, SHP and FFY co-estimated $\mathrm{CT}_{\max }$ in the lab. JB, MPB and SHP reviewed the literature. SHP did statistical analyses, and wrote the first draft of the manuscript. All authors contributed critically to the drafts, gave final approval for publication and declare no conflict of interest.

\section{Declaration of Competing Interest}

The authors declare that they have no known competing financial interests or personal relationships that could have appeared to influence the work reported in this paper.

\section{Acknowledgements}

Manuscript development funded through British Ecological Society 'Research Grant' 4496-5470 to SHP, and Spanish Ministry of Science grants CGL2011-26852 to MBA and SHP and CGL2017-89898-R to DRV. We thank Alicia Pérez Edo, Pedro Ballesteros, José Vicente Escobar and the University of Alcalá for logistic support during field and lab work, and Ilian Velikov for the lizard silhouettes. Permits for sampling and experiments granted by the following regional governments: Comunidad de Madrid (permit $=10 /$ 080485.9/16, Chapinería, Madrid), Gobierno de Aragón (INAGA/5000201/24/2016/3409, Portalet, Huesca), and Generalitat Valenciana (372/2015-VS(FAU15_038), El Saler, Valencia; and 2015/272-jvee, Peñagolosa, Castellón).

\section{Supplementary materials}

Supplementary material associated with this article can be found in the online version at doi:10.1016/j. baae.2020.08.001.

\section{References}

Araújo, M. B., \& Pearson, R. G. (2005). Equilibrium of species' distributions with climate. Ecography, 28, 693-695. doi:10.1111/j.2005.0906-7590.04253.x.

Araújo, M. B., Thuiller, W., \& Pearson, R. G. (2006). Climate warming and the decline of amphibians and reptiles in Europe. Journal of Biogeography, 33, 1712-1728. doi:10.1111/j.13652699.2006.01482.x.

Ault, T. R. (2020). On the essentials of drought in a changing climate. Science (New York, N.Y.), 368, 256-260. doi:10.1126/science.aaz5492.

Bartlett, M. S. (1937). Properties of sufficiency and statistical tests. Proceedings of the Royal Society A, 160, 268-282. doi:10.1098/rspa.1937.0109.

Beal, M. S., Lattanzio, M. S., \& Miles, D. B. (2014). Differences in the thermal physiology of adult Yarrow's spiny lizards (Sceloporus jarrovii) in relation to sex and body size. Ecology and Evolution, 4, 4220-4229. doi:10.1002/ece3.1297.

Belasen, A., Brock, K., Li, B., Chremou, D., Valakos, E., et al. (2017). Fine with heat, problems with water: Microclimate alters water loss in a thermally adapted insular lizard. Oikos (Copenhagen, Denmark), 126, 447-457. doi:10.1111/oik.03712.

Belliure, J. (2015). Lagartija colirroja - Acanthodactylus erythrurus. In A. Salvador, \& A. Marco (Eds.), Enciclopedia virtual de los vertebrados españoles. Madrid, Spain: Museo Nacional de Ciencias Naturales (http://www.vertebradosibericos.org).

Bennett, J. M., Calosi, P., Clusella-Trullas, S., Martínez, B., Sunday, J., et al. (2018). GlobTherm, a global database on thermal tolerances for aquatic and terrestrial organisms. Scientific Data, 5, 180022. doi:10.1038/sdata.2018.22.

Bonebrake, T. C., \& Mastrandrea, M. D. (2010). Tolerance adaptation and precipitation changes complicate latitudinal patterns of 
climate change impacts. Proceedings of the National Academy of Sciences, 107, 12581-12586. doi:10.1073/pnas.0911841107.

Bonetti, M. F., \& Wiens, J. J. (2014). Evolution of climatic niche specialization: A phylogenetic analysis in amphibians. Proceedings of the Royal Society B, 281, 20133229. doi:10.1098/ rspb.2013.3229.

Brattstrom, B. H. (1968). Thermal acclimation in anuran amphibians as a function of latitude and altitude. Comparative Biochemistry and Physiology, 24, 93-111. doi:10.1016/0010-406X (68)90961-4.

Bubliy, O. A., Kristensen, T. N., Kellermann, V., \& Loeschcke, V. (2012). Humidity affects genetic architecture of heat resistance. Drosophila melanogaster. Journal of Evolutionary Biology, 25, 1180-1188. doi:10.1111/j.14209101.2012.02506.x.

Buckley, L. B., Ehrenberger, J. C., \& Angilletta, M. J. (2015). Thermoregulatory behaviour limits local adaptation of thermal niches and confers sensitivity to climate change. Functional Ecology, 29, 1038-1047. doi:10.1111/1365-2435.12406.

Buckley, L. B., Hurlbert, A. H., \& Jetz, W. (2012). Broad-scale ecological implications of ectothermy and endothermy in changing environments. Global Ecology and Biogeography, 21, 873-885. doi:10.1111/j.1466-8238.2011.00737.x.

Burnham, K. P., \& Anderson, D. R. (2002). Model selection and multimodel inference (2nd ed.). New York: Springer Science, Business Media, LLC.

Calosi, P., Bilton, D. T., Spicer, J. I., Votier, S. C., \& Atfield, A. (2010). What determines a species' geographical range? Thermal biology and latitudinal range size relationships in European diving beetles (Coleoptera: Dytiscidae). Journal of Animal Ecology, 79, 194-204. doi:10.1111/ j.1365-2656.2009.01611.x.

Calsbeek, R., Knouft, J. H., \& Smith, T. B. (2006). Variation in scale numbers is consistent with ecologically based natural selection acting within and between lizard species. Evolutionary Ecology, 20, 377-394. doi:10.1007/s10682-006-0007-y.

Camacho, A., \& Rusch, T. W. (2017). Methods and pitfalls of measuring thermal preference and tolerance in lizards. Journal of Thermal Biology, 68, 63-72. doi:10.1016/j.jtherbio.2017.03.010.

Camargo, A., Sinervo, B., \& Sites, J. W. (2010). Lizards as model organisms for linking phylogeographic and speciation studies. Molecular Ecology, 19, 3250-3270. doi:10.1111/j.1365294X.2010.04722.x.

Chown, S. L., \& Gaston, K. J. (2016). Macrophysiology - progress and prospects. Functional Ecology, 30, 330-344. doi:10.1111/1365-2435.12510.

Chown, S. L., Sørensen, J. G., \& Terblanche, J. S. (2011). Water loss in insects: An environmental change perspective. Journal of Insect Physiology, 57, 1070-1084. doi:10.1016/j.jinsphys.2011.05.004.

Clusella-Trullas, S., Blackburn, T. M., \& Chown, S. L. (2011). Climatic predictors of temperature performance curve parameters in ectotherms imply complex responses to climate change. The American Naturalist, 177, 738-751. doi:10.1086/660021.

Clusella-Trullas, S., \& Chown, S. L. (2014). Lizard thermal trait variation at multiple scales: A review. Journal of Comparative Physiology B, 184, 5-21. doi:10.1007/s00360-013-0776-x.

Congdon, J. D., Ballinger, R. E., \& Nagy, K. A. (1979). Energetics, temperature and water relations in winter aggregated Sceloporus jarrovii (Sauria: Iguanidae). Ecology, 60, 30-35. doi:10.2307/1936464.
Cowles, R. B., \& Bogert, C. M. (1944). A preliminary study of the thermal requirements of desert reptiles. Bulletin of the American Museum of Natural History, 83, 261-296. doi:10.1086/394795.

Csárdi, G., \& Nepusz, T. (2006). The igraph software package for complex network research. InterJournal, Complex Systems, 1695 http://igraph.org.

Dasari, H. P., Salgado, R., Perdigao, J., \& Challa, V. S. (2014). A regional climate simulation study using WRF-ARW model over Europe and evaluation for extreme temperature weather events. International Journal of Atmospheric Sciences, 2014, 704079. doi:10.1155/2014/704079.

Dean, A., \& Voss, D. (1999). Design and analysis of experiments. Springer.

Diamond, S. E. (2017). Evolutionary potential of upper thermal tolerance: Biogeographic patterns and expectations under climate change. Annals of the New York Academy of Sciences, 1389, 5 19. doi:10.1111/nyas.13223.

Dupoué, A., Blaimont, P., Rozen-Rechels, D., Richard, M., Meylan, S., et al. (2020). Water availability and temperature induce changes in oxidative status during pregnancy in a viviparous lizard. Functional Ecology, 34, 475-485. doi:10.1007/ 10.1111/1365-2435.13481.

Dupoué, A., Rutschmann, A., Le Galliard, J. F., Clobert, J., Blaimont, P., et al. (2018). Reduction in baseline corticosterone secretion correlates with climate warming and drying across wild lizard populations. Journal of Animal Ecology, 87, 13311341. doi:10.1111/1365-2656.12843.

Dupoué, A., Rutschmann, A., Le Galliard, J. F., Miles, D. B., Clobert, J., et al. (2017). Water availability and environmental temperature correlate with geographic variation in water balance in common lizards. Oecologia, 185, 561-571. doi:10.1007/s00442-017-3973-6.

Frishkoff, L. O., Karp, D. S., Flanders, J. R., Zook, J., Hadly, E. A., et al. (2016). Climate change and habitat conversion favour the same species. Ecology Letters, 19, 1081-1090. doi:10.1111/ele.12645.

Garcia, R. A., Cabeza, M., Rahbek, C., \& Araújo, M. A. (2014). Multiple dimensions of climate change and their implications for biodiversity. Science (New York, N.Y.), 344, 1247579. doi:10.1126/science.1247579.

Garland, T., \& Adolph, S. C. (1994). Why not to do two-species comparative studies: Limitations on inferring adaptation. Physiological Zoology, 67, 797-828. doi:10.1086/ physzool.67.4.30163866.

Gaston, K. J., Chown, S. L., Calosi, P., Bernado, J., Bilton, D. T., et al. (2009). Macrophysiology: A conceptual reunification. The American Naturalist, 5, 595-612. doi:10.1086/605982.

Gilbert, A. L., \& Miles, D. B. (2019). Antagonistic responses of exposure to sublethal temperatures: Adaptive phenotypic plasticity coincides with a reduction in organismal performance. The American Naturalist, 194, 344-355. doi:10.1086/704208.

Goulet, C. T., Thompson, M. B., Michelangeli, M., Wong, B. B. M., Chapple, D. G., et al. (2017). Thermal physiology: A new dimension of the pace-of-life syndrome. Journal of Animal Ecology, 86, 1269-1280. doi:10.1111/1365-2656.12718.

Hawkins, B. A., Field, R., Cornell, H. V., Currie, D. J., Guégan, J.-F., et al. (2003). Energy, water, and broad-scale geographic patterns of species richness. Ecology, 84, 3105-3117. doi:10.1890/03-8006. 
Herrando-Pérez, S., Ferri-Yáñez, F., Monasterio, C., Beukema, W., Gomes, V., et al. (2019). Intraspecific variation in lizard heat tolerance alters estimates of climate impact. Journal of Animal Ecology, 88, 247-257. doi:10.1111/1365-2656.12914.

Herrando-Pérez, S., Monasterio, C., Beukema, W., Gomes, V., Ferri-Yáñez, F., et al. (2020). Heat tolerance is more variable than cold tolerance across species of Iberian lizards after controlling for intraspecific variation. Functional Ecology, 34, 631-645. doi:10.1111/1365-2435.13507.

Hertz, P. E., Arima, Y., Harrison, A., Huey, R. B., Losos, J. B., et al. (2013). Asynchronous evolution of physiology and morphology in Anolis lizards. Evolution; international journal of organic evolution, 67, 2101-2113. doi:10.1111/ evo.12072.

Huang, J., Yu, H., Guan, X., Wang, G., Guo, R., et al. (2016). Accelerated dryland expansion under climate change. Nature Climate Change, 6, 166-171. doi:10.1038/nclimate2837.

Kearney, M. R., Munns, S. L., Moore, D., Malishev, M., \& Bull, C. M. (2018). Field tests of a general ectotherm niche model show how water can limit lizard activity and distribution. Ecological Monographs, 88, 672-693. doi:10.1002/ecm.1326.

Kearney, M. R., Simpson, S. J., Raubenheimer, D., \& Kooijman, S. A. L. M. (2013). Balancing heat, water and nutrients under environmental change: A thermodynamic niche framework. Functional Ecology, 27, 950-966. doi:10.1111/ 1365-2435.12020.

Kellermann, V., Overgaard, Johannes, J., Hoffmann, Ary A., A. A., Fløjgaard, Camilla, C., Svenning, Jens-Christian, J.-C., et al. (2012). Upper thermal limits of Drosophila are linked to species distributions and strongly constrained phylogenetically. Proceedings of the National Academy of Sciences, 109, 16228-16233. doi:10.1073/pnas.1207553109.

Lancaster, L. T. (2016). Widespread range expansions shape latitudinal variation in insect thermal limits. Nature Climate Change, 6, 618-622. doi:10.1038/nclimate2945.

Latimer, A. M. (2007). Geography and resource limitation complicate metabolism-based predictions of species richness. Ecology, 88, 1895-1898. doi:10.1890/06-1931.1.

Le Galliard, J.-. F., Massot, M., Baron, J.-P., \& Clobert, J. (2012). Ecological effects of climate change on European reptiles. In J. F. Brodie, E. S. Post, D. F. Doak (Eds.), Wildlife conservation in a changing climate (pp. 179-203). London, UK: University of Chicago Press.

Li, Y., Li, X., Sandel, B., Blank, D., Liu, Z., et al. (2015). Climate and topography explain range sizes of terrestrial vertebrates. Nature Climate Change, 6, 498-504. doi:10.1038/nclimate2895.

Lillywhite, H. B. (2006). Water relations of tetrapod integument. Journal of Experimental Biology, 209, 202-226. doi:10.1242/ jeb.02007.

Lister, B. C., \& Garcia, A. (2018). Climate-driven declines in arthropod abundance restructure a rainforest food web. Proceedings of the National Academy of Sciences, 115, E10397E10406. doi:10.1073/pnas.1722477115.

Lorenzon, P., Clobert, J., Oppliger, A., \& John-Alder, H. (1999). Effect of water constraint on growth rate, activity and body temperature of yearling common lizard (Lacerta vivipara). Oecologia, 118, 423-430. doi:10.1007/s004420050744.

Lutterschmidt, W. I., \& Hutchison, V. H. (1997). The critical thermal maximum: Data to support the onset of spasms as the definitive end point. Canadian Journal of Zoology, 75, 15531560. doi:10.1139/z97-782.

Marvel, K., Cook, B. I., Bonfils, C. J. W., Durack, P. J., Smerdon, J. E., et al. (2019). Twentieth-century hydroclimate changes consistent with human influence. Nature, 569, 59-65. doi:10.1038/s41586-019-1149-8.

McCain, C. M., \& Colwell, R. K. (2011). Assessing the threat to montane biodiversity from discordant shifts in temperature and precipitation in a changing climate. Ecology Letters, 14, 12361245. doi:10.1111/j.1461-0248.2011.01695.x.

McLaughlin, J. F., Hellmann, J. J., Boggs, C. L., \& Ehrlich, P. R. (2002). Climate change hastens population extinctions. Proceedings of the National Academy of Sciences, 99, 6070-6074. doi:10.1073/pnas.052131199.

Mitchell, K. A., Boardman, L., Clusella-Trullas, S., \& Terblanche, J. S. (2017). Effects of nutrient and water restriction on thermal tolerance: A test of mechanisms and hypotheses. Comparative Biochemistry and Physiology, Part A: Molecular \& Integrative Physiology, 212, 15-23. doi:10.1016/ j.cbpa.2017.06.019.

Mora, C., Spirandelli, D., Franklin, E. C., Lynham, J., Kantar, M. B., et al. (2018). Broad threat to humanity from cumulative climate hazards intensified by greenhouse gas emissions. Nature Climate Change, 8, 1062-1071. doi:10.1038/ s41558-018-0315-6.

Muñoz, M. M., Langham, G. M., Brandley, M. C., Rosauer, D. F., Williams, S. E., et al. (2016). Basking behavior predicts the evolution of heat tolerance in Australian rainforest lizards. Evolution; International Journal of Organic Evolution, 70, 25372549. doi:10.1111/evo.13064.

Murphy, M. S., \& Denardo, D. F. (2019). Rattlesnakes must drink: Meal consumption does not improve hydration state. Physiological and Biochemical Zoology, 92, 381-385. doi:10.1086/ 704081.

Nadeau, C. P., \& Urban, M. C. (2019). Eco-evolution on the edge during climate change. Ecography,, 42, 1-18. doi:10.1111/ ecog.04404.

Nagy, K. A. (1972). Water and electrolyte budgets of a free-living desert lizard. Sauromalus Obesus. Journal of comparative physiology, 79, 39-62. doi:10.1007/BF00693617.

O'Brien, E. M. (2006). Biological relativity to water-energy dynamics. Journal of Biogeography, 33, 1868-1888. doi:10.1111/j.1365-2699.2006.01534.x.

Orlando, E. F., \& Guillette, L. J., Jr. (2001). A re-examination of variation associated with environmentally stressed organisms. Human Reproduction Update, 7, 265-272. doi:10.1093/ humupd/7.3.265.

Oufiero, C. E., Gartner, G. E., Adolph, S. C., \& Garland, T. (2011). Latitudinal and climatic variation in body size and dorsal scale counts in Sceloporus lizards: A phylogenetic perspective. Evolution; international journal of organic evolution, 65, 35903607. doi:10.1111/j.1558-5646.2011.01405.x.

Park, C.-. E., Jeong, S.-J., Joshi, M., Osborn, T. J., Ho, C.-H., et al. (2018). Keeping global warming within $1.5^{\circ} \mathrm{C}$ constrains emergence of aridification. Nature Climate Change, 8, 70-74. doi:10.1038/s41558-017-0034-4.

Peterson, C. C. (1996). Ecological energetics of the desert tortoise (Gopherus Agassizii): Effects of rainfall and drought. Ecology, 77, 1831-1844. doi:10.2307/2265787.

Phillips, B. L., Muñoz, M. M., Hatcher, A., Macdonald, S. L., Llewelyn, J., et al. (2016). Heat hardening in a tropical lizard: 
Geographic variation explained by the predictability and variance in environmental temperatures. Functional Ecology, 30, 1161-1168. doi:10.1111/1365-2435.12609.

Pinsky, M. L., Eikeset, A. M., McCauley, D. J., Payne, J. L., \& Sunday, J. M. (2019). Greater vulnerability to warming of marine versus terrestrial ectotherms. Nature, 569, 108-111. doi:10.1038/s41586-019-1132-4.

Pintor, A. F. V., Schwarzkopf, L., \& Krockenberger, A. K. (2016). Hydroregulation in a tropical dry-skinned ectotherm. Oecologia, 182, 925-931. doi:10.1007/s00442-016-3687-1.

Pirtle, E. I., Tracy, C. R., \& Kearney, M. R. (2019). Hydroregulation: A neglected behavioral response of lizards to climate change? In V. Bels, \& A. Russell (Eds.), Behavior of lizards (pp. 343-374). Boca Raton, Florida: CRC Press, Taylor \& Francis Group.

Wollenberg Valero, K. C., Marshall, J. C., Bastiaans, E., Caccone, A., Camargo, A., et al. (2019). Patterns, mechanisms and genetics of speciation in reptiles and amphibians. Genes, 10, 646. doi:10.3390/genes10090646.

Wright, C. D., et al. (2013). Meal consumption is ineffective at maintaining or correcting water balance in a desert lizard, Heloderma suspectum. Journal of Experimental Biology, 216, 1439-1447. doi:10.1242/jeb.080895.

Qiu, W. (2018). Package 'powerMediation'. https://cran.r-project. org/web/packages/powerMediation

$R$ Core Team. (2020). $R$ : A language and environment for statistical computing. $R$ Foundation for statistical computing, Vienna, Austria. www.R-project.org

Prieto-Ramirez, A. M., Pe'er, G., Rödder, D., \& Henle, K. (2018). Realized niche and microhabitat selection of the eastern green lizard (Lacerta viridis) at the core and periphery of its distribution range. Ecology and Evolution, 8, 11322-11336. doi:10.1002/ece3.4612.

Razgour, O., Persey, M., Shamir, U., \& Korine, C. (2018). The role of climate, water and biotic interactions in shaping biodiversity patterns in arid environments across spatial scales. Diversity and Distributions, 24, 1440-1452. doi:10.1111/ddi.12773.

Ribeiro, P. L., Camacho, A., \& Navas, C. A. (2012). Considerations for assessing maximum critical temperatures in small ectothermic animals: Insights from leaf-cutting ants. PloS One, 7, e32083. doi:10.1371/journal.pone.0032083.

Romero-Diaz, C., Breedveld, M. C., \& Fitze, P. S. (2017). Climate effects on growth, body condition, and survival depend on the genetic characteristics of the population. The American Naturalist, 190, 649-662. doi:10.1086/693780.

Rozen-Rechels, D., Badiane, A., Agostini, S., Meylan, S., \& Le Galliard, J.-F. (2020). Water restriction induces behavioral fight but impairs thermoregulation in a dry-skinned ectotherm. Oikos (Copenhagen, Denmark), 129, 572-584. doi:10.1111/ oik.06910.

Rozen-Rechels, D., Dupoué, A., Lourdais, O., Chamaillé-Jammes, S., Meylan, S., et al. (2019). When water interacts with temperature: Ecological and evolutionary implications of thermo-hydroregulation in terrestrial ectotherms. Ecology and Evolution, 9, 10029-10043. doi:10.1002/ ece 3.5440 .

Russo, A., Gouveia, C., Dutra, E., Soares, P. M. M., \& Machado Trigo, R. (2019). The synergy between drought and extremely hot summers in the Mediterranean. Environmental Research Letters, 14, 014011. doi:10.1088/1748-9326/aaf09e.
Ryan, M. J., Latella, I. M., Giermakowski, J. T., Snell, H., Poe, S., et al. (2016). Too dry for lizards: Short-term rainfall influence on lizard microhabitat use in an experimental rainfall manipulation within a piñon-juniper. Functional Ecology, 30, 964-973. doi:10.1111/1365-2435.12595.

Sánchez-Bayo, F., \& Wyckhuys, K. A. G. (2019). Worldwide decline of the entomofauna: A review of its drivers. Biological Conservation, 232, 8-27. doi:10.1016/j.biocon.2019.01.020.

Scheffers, B. R., Edwards, D. P., Diesmos, A., Williams, S. E., \& Evans, T. A. (2014). Microhabitats reduce animal's exposure to climate extremes. Global Change Biology, 20, 495-503. doi: $10.1111 / \mathrm{gcb} .12439$.

Schulte-Hostedde, A. I., Zinner, B., Millar, J. S., \& Hickling, G. J. (2005). Restitution of mass-size residuals: Validating body condition indices. Ecology, 86, 155-163. doi:10.1890/04-0232.

Sears, M. W., Raskin, E., \& Angilletta, M. J. (2011). The world is not flat: Defining relevant thermal landscapes in the context of climate change. Integrative and Comparative Biology, 51, 666-675. doi:10.1093/icb/icr111.

Siepielski, A. M., Morrissey, M. B., Buoro, M., Carlson, S. M., Caruso, C. M., et al. (2017). Precipitation drives global variation in natural selection. Science (New York, N.Y.), 355, 959962. doi:10.1126/science.aag2773.

Sinclair, B. J., Marshall, K. E., Sewell, M. A., Levesque, D. L., Willett, C. S., et al. (2016). Can we predict ectotherm responses to climate change using thermal performance curves and body temperatures? Ecology Letters, 19, 1372-1385. doi:10.1111/ ele. 12686.

Soule, M. (1966). Trends in the insular radiation of a lizard. The American Naturalist, 100, 47-64. doi:10.1086/282399.

Sousa-Guedes, D., Arenas-Castro, S., \& Sillero, N. (2020). Ecological niche models reveal climate change effect on biogeographical regions: The Iberian Peninsula as a case study. Climate, 8, 42. doi:10.3390/cli8030042.

Speybroeck, J., Beukema, W., Bok, B., Van Der Voort, J., \& Velikov, I. (2016). Field guide to the amphibians and reptiles of britain and europe.. London, UK: Bloomsboury Publishing.

Sugiura, N. (1978). Further analysis of the data by Akaike's information criterion and the finite corrections. Communications in Statistics, Theory and Methods, A7, 13-26. doi:10.1080/ 03610927808827599.

Sunday, J. M., Bates, A. E., \& Dulvy, N. K. (2012). Thermal tolerance and the global redistribution of animals. Nature Climate Change, 2, 686-690. doi:10.1038/nclimate1539.

Sunday, J. M., Bates, A. E., Kearney, M. R., Colwell, R. K., Dulvy, N. K., et al. (2014). Thermal-safety margins and the necessity of thermoregulatory behavior across latitude and elevation. Proceedings of the National Academy of Sciences, 111, 5610-5615. doi:10.1073/pnas.1316145111.

Thomas, C. D., \& Lennon, J. J. (1999). Birds extend their ranges northwards. Nature, 399. doi:10.1038/20335 213-213.

Trenberth, K. E., Dai, A., van der Schrier, G., Jones, P. D., Barichivich, J., et al. (2013). Global warming and changes in drought. Nature Climate Change, 4, 17-22. doi:10.1038/nclimate2067.

Valladares, F., Matesanz, S., Guilhaumon, F., Araújo, M. B., Balaguer, L., et al. (2014). The effects of phenotypic plasticity and local adaptation on forecasts of species range shifts under climate change. Ecology Letters, 17, 1351-1364. doi:10.1111/ ele. 12348 . 
Vamosi, J. C., Armbruster, W. S., \& Renner, S. S. (2014). Evolutionary ecology of specialization: Insights from phylogenetic analysis. Proceedings of the Royal Society B, 281, 20142004. doi:10.1098/rspb.2014.2004.

VanDerWal, J., Murphy, H. T., Kutt, A. S., Perkins, G. C., Bateman, B. L., et al. (2013). Focus on poleward shifts in species' distribution underestimates the fingerprint of climate change. Nature Climate Change, 3, 239-243. doi:10.1038/nclimate1688.
Wang, Y., Zeng, Z.-G., Li, S.-R., Bi, J.-H., \& Du, W.-G. (2016). Low precipitation aggravates the impact of extreme high temperatures on lizard reproduction. Oecologia, 182, 961-971. doi:10.1007/s00442-016-3727-x.

Wegener, J. E., Gartner, G. E. A., \& Losos, J. B. (2014). Lizard scales in an adaptive radiation: Variation in scale number follows climatic and structural habitat diversity in Anolis lizards. Biological Journal of the Linnean Society, 113, 570-579. doi:10.1111/bij.12380.

Available online at www.sciencedirect.com

ScienceDirect 